\title{
Synthesis of new metronidazole derivatives with suspected antimicrobial activity
}

\author{
Yasser F. Mustafa* ${ }^{*}$ Karam A. Al - dabbagh** Manal F. Mohammed** \\ ${ }^{*}$ Department of Pharmaceutical Sciences, ${ }^{* *}$ Department of Pharmacology, College of Pharmacy, University of \\ Mosul.

\begin{tabular}{|c|c|}
\hline Received: & Accepted \\
\hline & \\
\hline
\end{tabular}

\section{ABSTRACT}

Metronidazole has a bactericidal effect against many anaerobic gram positive and gram negative bacteria, but has no activity against aerobic bacteria.

Metronidazole activity is mostly contributed to its reduced form that produced from anaerobic reduction inside the micro-organisms.

In this research, the reduced form of metronidazole was synthesized and termed compound ( I ) which diazonated to form a diazonium interme-diate, this intermediate coupled with two phenolic compounds to give compounds ( II ) and ( III ) which are azo derivatives.

The structures of these compounds were identified by physical and spectroscopic ( U.V. and FTIR ) techniques.

The antibacterial activity of the synthesized compounds were examined against two aerobic gram positive bacteria ( Staphylococcus aureus, Streptococcus pneumoniae ); two aerobic gram negative bacteria (Pseudomonas aeruginosa, Escherichia coli ) and one anaerobic gram positive bacteria ( Clostridium Perfringens ) by using two techniques: dilution and disc diffusion methods.

Opposite to our expectance, these products showed no antibacterial activity against the tested bacteria at the concentrations used.

الخلاصة

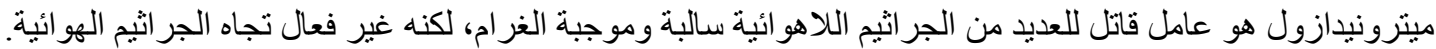

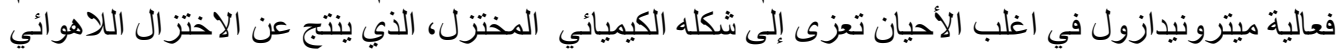

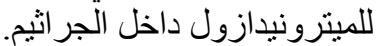

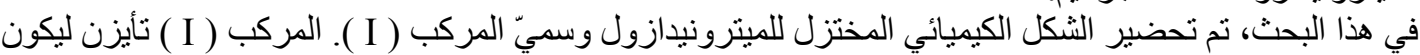
المركب الدايزوني الوسطي الذي باقتر انه مع مركبين من الفينو لات كون المركيين ( II ) و ( III ) ) و لهما من مشتنقات الآزو.

تم تشخيص المركبات المحضرة بالوسائل الفيزيائية والطيفية المتوفرة وتم دراسة الفعالية المضادة للجر اثيم للمركبات

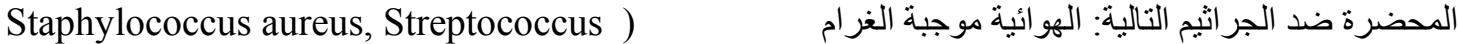

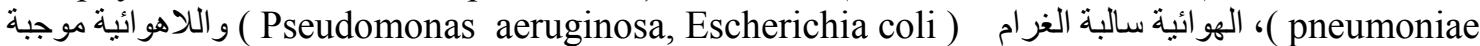
الغر ام (Clostridium Perfringens ) باستعمال تقنيتي التخفيف و الانتشار. لقد أظهرت النتائج وبعكس المتوقع بان المركبات المحضرة لم تبدي أبي نشاط كمضاد جرثومي ضد الجر اثيم المستخدمة للبحث ضمن التر اكيز المستخدمة. 
I etronidazole is the prototype of aomycin (nitro imidazole) anti-infective agents. Nakumura was discovered the aomycin group; Horie was demonstrated the anti-infective property of these compounds leading to their chemical synthesis in various laboratories throughout the world.'

Metronidazole is a bactericidal against anaerobic bacteria, its spectrum of activity includes the anaerobic gram negative bacilli including most Bacteroides, Fusobacterium and Veillonella, anaerobic gram positive cocci including Peptococcus and Peptidostreptococcus species and anaerobic gram positive bacilli including Clostridium and Eubacterium species. '.

Metronidazole is also active against E.histolytica and G.lamblia. It acts primarily against the trophozoite forms and has limited activity against the encysted forms $(r)$.

The mechanism of metronidazole activity against anaerobic micro-organisms occurs through four steps. First of all is the entry into the micro-organism; metronidazole is a low molecular weight compound which diffuses across cell membranes of anaerobic microorganisms ${ }^{r}$.

The second step is a reductive activation by intracellular transport proteins; metronidazole is reduced by the pyruvate- ferredoxin oxidereductase (PFOR) system in the mitochondria of obligate anaerobes, which alters its chemical structure.

Pyruvate-ferredoxin oxidoreductase normally generates ATP via oxidative decarboxylation of pyruvate. With metronidazole in the cellular environment, its nitro group acts as an electron sink, capturing electrons that would usually be transferred to hydrogen ions in this cycle.

Reduction of metronidazole creates a concentration gradient which drives uptake of more drug, and promotes formation of intermediate compounds and free radicals that are toxic to cell. ${ }^{\xi, 0}$.

Then the reduced intermediate particle interact with host cell DNA, resulting in DNA strand breakage and fatal destabilization of the DNA helix ${ }^{\mathrm{r} Y}$, and the last step is the breakdown of cytotoxic intermediate products into inactive end products..

r..A Mosul College of Pharmacy
The resistance to metronidazole have been increased ${ }^{9-1 r}$. Two distinct types of resistance have been recognized for metronidazole and named aerobic and anaerobic according to conditions required for demonstration of resistance by in vitro susceptibility assays. '

The aerobic resistance is manifested only if some oxygen is present. Under anaerobic conditions, the resistant organisms succumb to the drug, as they possess a functional drugactivating pathway.

The resistance apparently results from defective oxygen scavenging and subsequent interference of intracellular oxygen with the drug activation. ${ }^{\circ}$

Alternatively, defective redox properties of ferredoxin or decreased ferredoxin level due to alter transcription of the ferredoxin gene have been proposed as potential mechanisms, However, a causal relationship of these alterations with the aerobically resistant phenotype has not been convincingly demonstrated.'

The resistant anaerobic micro-organisms are typically deficient in drug activation system because of the modification of proteins involved in pathways responsible for the reductive activation of the drug ${ }^{\text {'v. }}$.

The loss of ( PFOR ) activity holds for a key attribute of the anaerobic resistance but in vitro obtained lines deficient in ( PFOR ) activity showed only low levels of anaerobic resistance to metronidazole, thus indicating involvement of an additional pathway(s) which can provide electrons for the drug reduction.'

Therefore, there is an urgent need to create new metronidazole deriva-tives to overcome the problem of bacterial resistance to metronidazole.

The laboratory reduction of a nitro-containing compound proceeds either by catalytic hydrogenation via molecular hydrogen or by chemical reduction via acid and metal.

Hydrogenation of a nitro-containing compound to a primary amino derivative takes place smoothly when a solution of the nitro compound in alcohol was shaken with finely divided nickel or platinum under a supply of hydrogen gas.

This method can not be used because metronidazole contains some easily 
hydrogenated groups $\left(19^{*}\right)$, Therefore, the was carried out by adding a mixture of conc. hydrochloric acid and a metal.

When a primary aromatic amine (dissolved or suspended in a cold aqueous mineral acid) was treated with sodium nitrite, diazonium salt will be formed. Since the diazonium salts are slowly decomposed even at ice-bath temperatures, the solutions of diazonium salts were used immediately after their preparations ()$\left.^{9^{* *}}\right)$.

The azo compounds were prepared by coupling reaction which involves the interaction of a diazonium salt and phenol in slightly alkaline medium ${ }^{r}$.

The biological importance of azo compounds was well known for their use as antineoplastics, ${ }^{r} \quad$ antidiabetics, $^{r r} \quad$ and

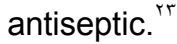

It has been found that the incorporation of azo linkage with pyrimidine and pyrazole as coupling compounds may decrease the antibacterial activity ${ }^{r \varepsilon}$ while the incorporation with phenyl ring contains an electronwithdrawing group may increase the antibacterial activity of azo linkage. ${ }^{\text {ro }}$

In this research, the antibacterial activity of azo linkage incorporates with phenyl ring containing an electron-donating group(s) and with imidazole ring containing electrondonating groups was examined.

The determination of micro-organism susceptibility to the new synthesized compounds were carried out by two principal methods; dilution and diffusion methods.

These methods can be employed to estimate either the potency of the new synthesized compounds as antibacterial agents or the susceptibility of the tested bacteria to these compounds ( $Y$ T).

\section{Materials and instruments}

\section{Materials}

The parent compound (metronidazole ) was supplied from a Ninevah Drug Industry ( NDI ). All other chemicals used in preparations were supplied from Flukacompany.

Instruments preferred chemical reduction of metronidazole

- Melting points were determined on electrothermal CIA $q$ r.. melting point apparatus and they are uncorrected.

- The ultraviolet spectra were obtained via carrywinn UV varian U.V. - visible spectrophotometer ( Australia).

- The infrared absorptions were recorded by Buck ... scientific I.R. spectrophotometer ( U.S.A. ).

- Thin-layer chromatography ( TLC ) was carried out on TLC plastic sheets silica gel r. Fo precoated , $r \cdot \times r \cdot \mathrm{cm}$, layer thickness $\because r \mathrm{~mm}$.

The spots on the chromatograms were localized using U.V. light (rr4 nm)(Whatmann ). The solvent system employed for separation was (Tc) which composed from chloroform: methanol

$(9: 1)$.

- $\quad$ Structures were drawn by chemdraw office r... software.

\section{Experimental methods}

\section{- Synthesis of compound I}

A $(100 \mathrm{ml})$ of water and or $\mathrm{g}$ of grease-free iron were placed in a $(0 \cdots \mathrm{ml})$ round bottom flask. The mixture was warmed on a water bath to about $\left(r \cdot{ }^{\circ} \mathrm{C}\right)$. A ( $\leqslant r . r \circ g, \cdot r \leqslant V$ mole) of metronidazole was divided into parts, each part weights about $(r g)$.

Two grams of metronidazole and $(l \cdot \mathrm{ml})$ of conc. $\mathrm{HCl}$ were added to the previous warmed mixture, the temperature should remain between $\left(\wedge \cdot-9 \cdot{ }^{\circ} \mathrm{C}\right)$ throughout the reaction.

Every r. minutes; two grams of metronidazole was added with stiring. After the last addition, the mixture was stirred for $r$. minutes

The mixture was cooled; filtered; and the product washed with cold water three times; then recrystalized from a mixture of chloroform : ethanol $(1: 1)$.

The compound purity was established by thin-layer chromatography using Tc solvent and the TLC result showed that only a single spot was observed. 


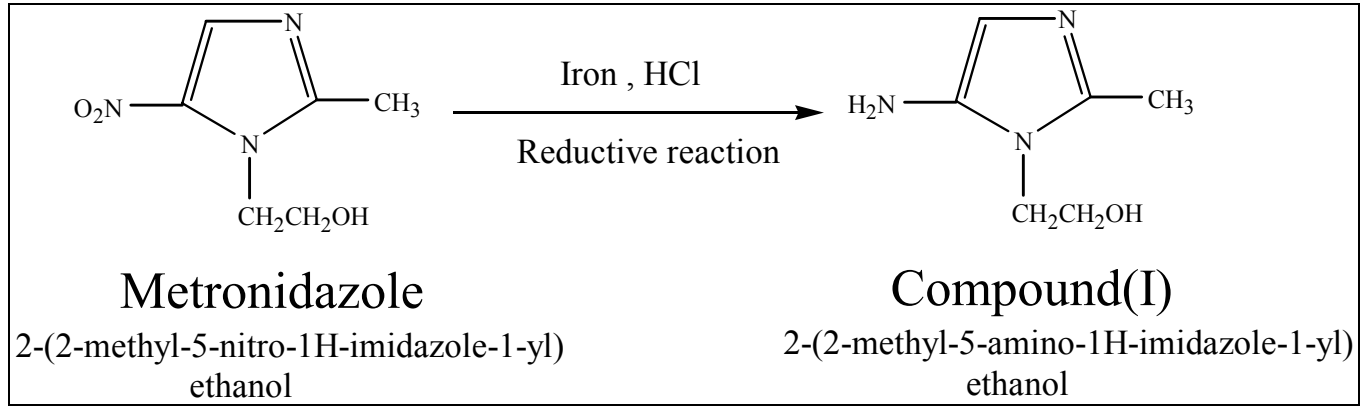

Scheme 1 . Synthesis of compound (I).

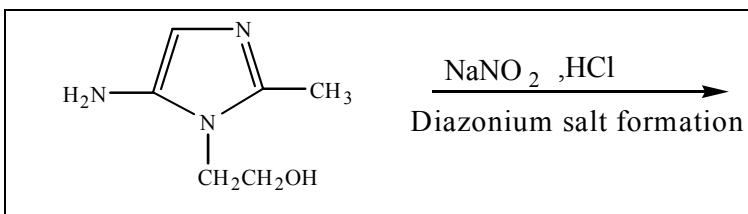

Compound(I)

2-(2-methyl-5-amino-1H-imidazole-1-yl) ethanol

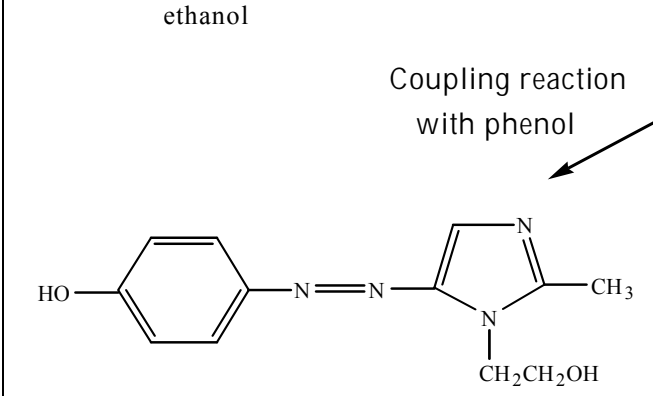

Compound (II)

2-(2-methyl-5-[(4'-hydroxyphenyl)azo]

-1H-imidazole-1-yl)ethanol.<smiles></smiles>

Intermediate
Coupling reaction with o- cresol

Scheme r. Synthesis of compounds ( II ) and ( III ).

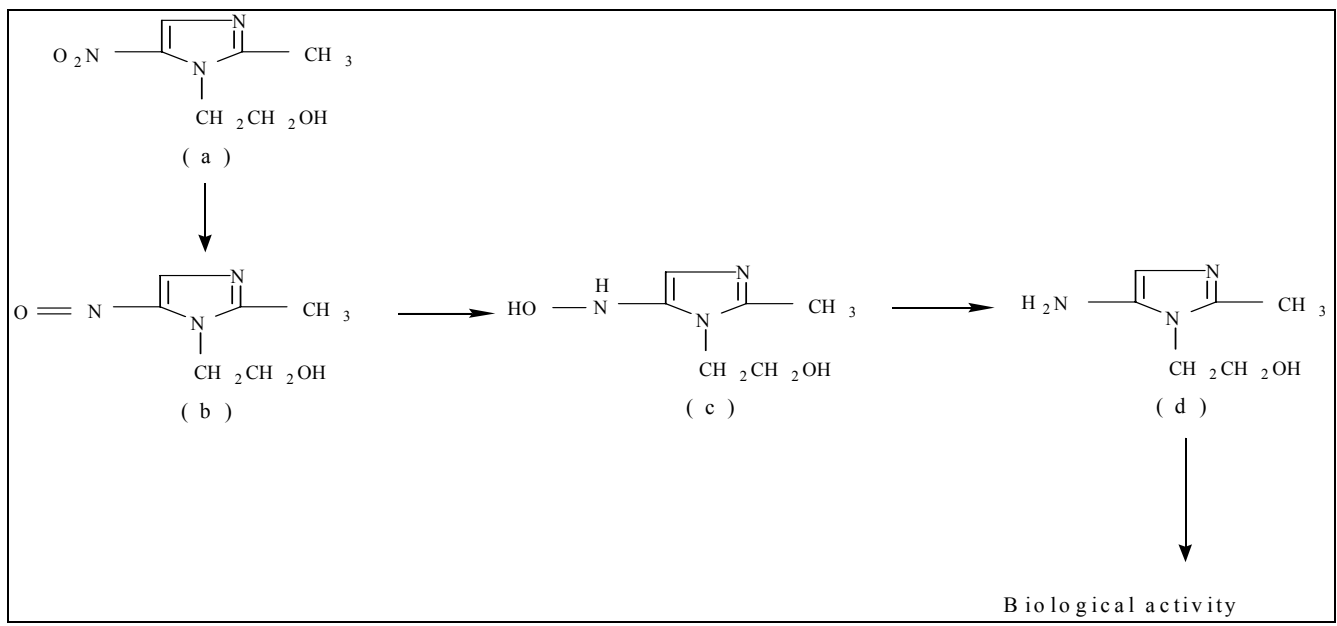

Scheme $r$. Reduction of metronidazole (a) to form nitroso(b), hydroxylamine(c) and amino(d) derivatives in an anaerobic bacteria.

Compound I has the following data: the m.p. was $\left.17 \Lambda_{-}\right) \vee \cdot{ }^{\circ} \mathrm{C}$, the percentage of yield 
was $v r \%$, the molecular formula was established as $\mathrm{C}_{\uparrow} \mathrm{H}_{1}, \mathrm{ON}_{r}$ and the $\mathrm{Rf}$ value was.,$r \leq$.

While for Metronidazole, the m.p. was (101 $17 .{ }^{\circ} \mathrm{C}$ ), the molecular formula was $\mathrm{C}_{4} \mathrm{H}_{4} \mathrm{O}_{4} \mathrm{~N}_{r}$ and the Rf value was $\cdot r^{r v}$.

- Synthesis of compounds II and III :

A $(\vee . \circ \mathrm{Ng}, \because .0 \leqslant$ mole) of compound I was dissolved in a mixture of equal quantity ( $17 \mathrm{ml})$ of each conc. $\mathrm{HCl}$ and water in a large beaker; the resulted solution was cooled by immersing in a bath of crush ice; throughout the reaction, the reaction temperature should be remain below $0^{\circ} \mathrm{C}$

The cold solution of $\Sigma \mathrm{g}, \cdot . .0 \wedge$ mole sodium nitrite in $r$. $m l$ water was placed in a separating funnel and then added drop by drop to the stirred solution in an ice bath; the reaction temperature should be remain below $1 .{ }^{\circ} \mathrm{C}$ by adding few grams of crushed ice when necessary.

The resulted solution was stirred very slowly for $\triangle$ minutes; on the other hand, the phenolic solution was prepared by mixing $0 . .0 \mathrm{~g}, \cdot .0$ \& mole of phenol with $\leqslant 0 \mathrm{ml}$ of $1 . \% \mathrm{NaOH}$ in a beaker immersed in the ice bath.

The solution was vigorously stirred and the temperature kept below $0^{\circ} \mathrm{C}$; this can be assisted by a direct addition of crushed ice.

The cold diazonium salt solution (with few grams of crushed ice) was placed in a separating funnel and was added drop by drop to the stirred phenolic solution in an ice bath; yellow color will developed and yellow crystals soon separated giving compound II .

After the diazonium salt solution was added; allow the mixture to stand in an ice bath for $r$. minutes; filtered off and washed the crystals three times with cold water, then recrystalized from ethanol.

The compound purity was established by thin-layer chromatography using Tc solvent and the TLC result showed that only a single spot was observed.

The previous procedure can be carried out by using o-cresol instead of phenol to give compound( III ).

Compound II has the following data: the m.p. was $1 r \cdot-1 r^{\circ} \mathrm{C}$, the percentage of yield was ( $\urcorner \leqslant \%)$, the molecular formula was established as $\quad \mathrm{C}_{1} \mathrm{H}_{1} \mathrm{O}_{r} \mathrm{~N}_{\varepsilon}$ and the Rf value was $\cdot . r$.

While for compound III, the m.p. was ( $\leq \leqslant$. $1 \leqslant \wedge^{\circ} \mathrm{C}$ ), the percentage of yield was $\vee 1 \%$ the molecular formula was established as $\mathrm{C}_{r}$ $\mathrm{H}_{17} \mathrm{O}_{\uparrow} \mathrm{N}_{\varepsilon}$ and the Rf value was $\cdot . r \wedge$.

\section{Antimicrobial study}

- Sensitivity test method for aerobic bacteria:
This test proceeds by transferring $\varepsilon_{-0}$ pure colonies from the tested bacteria (three isolates for each bacterial strain) into nutrient broth media which incubated at $r v^{\circ} \mathrm{C}$ for $1 \leqslant-17$ hours; then the bacterial suspension was diluted with normal saline and compared with controlled tube which contains $1 \cdot^{\wedge}$ cells $/ \mathrm{cm}^{r}$.

From the tested bacterial suspension, $(\cdot$. $\mathrm{cm}^{r}$ ) was inoculated into a nutrient agar media and spread on the disc surface by using a sterile

cotton swab, the discs were incubated at $r v^{\circ} \mathrm{C}$ for $r$. minutes, during this period, diffusion was occur.

A sterile filter paper disc with $(7 \mathrm{~mm})$ in radius saturated with different concentrations ( 1 . 0 , $r_{0}, \bullet, 1 \cdots, r_{\cdots} \mathrm{mg} / \mathrm{ml}$ ) was placed by using a sterile forceps on the bacterial discs, the resulted discs were incubated at $r v^{\circ} \mathrm{C}$ for ( 1 17 hours); then the inhibition zones were identified.

Triplet runs were carried out for two gram positive bacteria (Staphylococcus aureus , Streptococcus pneumoniae); and two gram negative bacteria( Pseudomonas aeruginosa , Escherichia coli).

- Sensitivity test method for anaerobic bacteri

Successful culture of anaerobes requires fresh media and reliable system for maintaining an anaerobic atmosphere, which should included 1. $\%$ carbon dioxide. This system is unavailable in our college laboratory, therefore, anaerobic bacteria discs which contain Clostridium Perfringens were supplied from general health laboratory in Mosul.

As in a sensitivity test for aerobic bacteria, the same concentrations were applied and triplet runs were carried out .

\section{Results and discussion}

- Metronidazole and compound I:

Metronidazole is a potent anaerobic bactericidal agent, its activity is mostly contributed to its reduced form that produced from anaerobic reduction inside the microorganisms, therefore, metronidazole is ineffective against aerobic bacteria due to lack the ability to form the active metabolite (reduced form).

In anaerobic micro-organisms, metronidazole was metabolized as shown in scheme ( $r)$. Beaulieu B. B. indicated that there is a direct correlation between bactericidal activity of the 
metronidazole and the speed of reduced form production $^{(\uparrow \wedge)}$.

The research proposed that the reduced form of metronidazole (compound I) has enhanced bactericidal activity against anaerobic bacteria, if proven; the reduced form may be more potent in terms of concentration than parent drug.

In addition, metronidazole is ineffective against aerobic bacteria due to the inability of these bacteria to reduce the nitro group of metronidazole to form the active metabolite.

The research proposed that the application of an active metabolite of metronidazole to the aerobic bacteria may cause antibacterial effect; if proven; the compound I may have broader spectrum of activity than the parent drug .

The chemical reduction of metronidazole in laboratory was carried out by adding conc. $\mathrm{HCl}$ to a mixture of metronidazole and iron.

Compound ( 1 ) was generally formed in a high yield (about $\vee\ulcorner \%$ ) as light brown crystals.

I.R. spectrum was in quite agreement with the structure of compound I, the I.R. spectrum shows the principal following peaks:

rrrs $\mathrm{cm}^{-1}(\mathrm{br})$ for strong intra molecular hydrogen bounding for

hydroxyl group of the ethanol side chain; $r . .1$ $\mathrm{cm}^{-1}(\mathrm{~m})$ for $(\mathrm{C}-\mathrm{H})$ of

$\mathrm{CH}_{r}$ group; r9ov cm $\mathrm{cm}^{-1}(\mathrm{~m})$ for $(\mathrm{C}-\mathrm{H})$ of $\mathrm{CH}_{r}$ group at position $r$ of

imidazole ring; $11.0 \mathrm{~cm}^{-1}(\mathrm{~m})$ for tri substituted imidazole ring;

$r \varepsilon / \mathrm{Cm}^{-1}(\mathrm{~m})$ for $(\mathrm{N}-\mathrm{H})$ of primary amine; rrq $\mathrm{cm}^{-1}$ (br)for primary amino salt $\left({ }^{+} \mathrm{NH}_{r} \mathrm{Cl}^{-}\right)$.

The appearance of absorption band at $r \varepsilon 1 \mathrm{vcm}^{-1}$ confirmed the reduction of a nitro group of metronidazole into a primary amino group.

The U.V. spectrum of compound I in an aqueous acidic solution shows $\lambda \max$ at $r \vee q$ $\mathrm{nm}$, while the $\lambda \max$ of metronidazole in an aqueous acidic solution was at $r v v \mathrm{~nm}^{(\mathrm{rq})}$.

- Synthesis of compounds II and III:

A primary aromatic amine ( compound I ) was dissolved in a cold aqueous mineral acid solution then treated with sodium nitrite to form a diazonium salt, this process called diazotization of primary amine.

Two important points must be taken into consideration in the preparation of diazonuim salts; which are: the amine is comparatively a weak base, so that, a certain amount of amine will be produced by salt hydrolysis unless an excess of acid present; and the reaction mixture must be kept very cold during the process (the reaction is exothermic); otherwise, the diazonium salt may be partially converted into the corresponding hydroxyl compound.

The aromatic ring undergoes attack by the diazonium ion must be in general contains a powerful electron-donating group( $-\mathrm{OH}$, $-\mathrm{NH}_{\mathrm{r}},-\mathrm{NHR}$ ).

Substitution usually occurs at para position to the activating group. According to this fact, phenol and o-cresol were chosen.

The most important point in the coupling reaction using phenol is the degree of acidity. Phenol is appreciably acidic in aqueous solutions and exists in equilibrium with phenoxide ion; thus; in the preparation of compounds II and III, a low acidity level which give high amounts of ionized phenols to be coupled, and then a relatively high percentage of yields were obtained.

For compound II, the I.R. shows the following principal peaks:

rror $\mathrm{cm}^{-1}(\mathrm{~m})$ for weak inter molecular hydrogen bounding of the phenolic hydroxyl group; $1199 \mathrm{~cm}^{-1}(w)$ for disubstituted aromatic ring; 1 V० $\leqslant \mathrm{cm}^{-1}(w)$ for tri substituted imidazole ring; $171 \mathrm{r} \mathrm{cm}^{-1}(\mathrm{~m})$ for $(\mathrm{C}=\mathrm{C})$ of imidazole ring; $1 \leqslant 9 \leqslant \mathrm{~cm}^{-1}(\mathrm{w})$ for ($\mathrm{N}=\mathrm{N}$-) group (unsymmetrical $\mathrm{p}$-substituted azobenzene); $1 \cdot 10 \mathrm{~cm}^{-1}(\mathrm{~m})$ for $(\mathrm{C}-\mathrm{N})$.

The disappearance of absorption band at $r \leqslant 1 \mathrm{~cm}^{-1}$ of primary amine and the appearance of a weak absorption band at $1 \leq 9$ 纟 $\mathrm{cm}^{-1}$ of azo group confirmed the formation of azo compound, these data were quite in agreement with the structure of compound II .

The U.V. spectrum of compound II in an aqueous acidic solution shows the $\lambda \max$ at MIr $\mathrm{nm}$, the increasing in the magnitude of $\lambda$ max may indicates the presence of a new conjugation.

For compound III , the I.R. shows the following principal peaks: rrr. $\mathrm{cm}^{-1}$ (br)for strong inter molecular hydrogen bounding of the phenolic hydroxyl group; $\mu 1.1 \mathrm{~cm}^{-1}(\mathrm{w})$ for (C-H) of aromatic ring; rq० $\mathrm{rm}^{-1}(\mathrm{w})$ for $(\mathrm{C}-\mathrm{H})$ of methylene group; $171 \leqslant \mathrm{~cm}^{-1}(\mathrm{~m})$ for $(\mathrm{C}=\mathrm{C})$ of 
imidazole ring; I $\leqslant \wedge \vee \mathrm{cm}^{-1}(\mathrm{w})$ for $(-\mathrm{N}=\mathrm{N}-)$ group (unsymmetrical p-substituted azobenzene); I $r \wedge \varepsilon \mathrm{cm}^{-1}(\mathrm{~s})$ for strong interaction between (O$\mathrm{H})$ bending and $(\mathrm{C}-\mathrm{O})$ stretching of phenol; 1. $v \leqslant \mathrm{~cm}^{-1}(\mathrm{~m})$ for $(\mathrm{C}-\mathrm{N})$.

The disappearance of absorption band at $r \varepsilon 1 \mathrm{Vm}^{-1}$ of primary amine and the appearance of a weak absorption band at I $\leqslant \wedge V$ $\mathrm{cm}^{-1}$ of azo group confirmed the formation of azo compound, these data were quite in agreement with the structure of compound ( III ).

The U.V. spectrum of compound ( III ) in an aqueous acidic solution shows the $\lambda \max$ at rir $\mathrm{nm}$, the increasing in the magnitude of $\lambda$ max may indicates the presence of a new conjugation.

\section{- In vitro antibacterial assay}

The new metronidazole compounds( I ,II and III ) were tested in vitro for their antibacterial activity against five strains of bacteria which are: Staphylococcus aureus, Streptococcus pneumoniae, Pseudomonas aeruginosa, Escherichia coli and Clostridium Perfringens by using different concentrations of these compounds ( $1 r .0, r_{0}, 0,1 \cdots$ and $\left.r \cdots \mathrm{mg} / \mathrm{ml}\right)$. Opposite to our expectance, no antibacterial activity for these compounds were detected.

\section{Conclusion}

In this research, three new metronidazole derivatives were synthesized. The compound ( l ) $\left\{\mathrm{r}_{-}\left(\mathrm{r}\right.\right.$-methyl-o-amino- $\mathrm{H}_{-}$imidazole- $\mathrm{yl}$ )ethanol\} was prepared by reducing metronidazole $\quad\{r-(\quad r$-methyl-॰-nitro- $) \mathrm{H}$ imidazole- - -yl)ethanol\} via conc. $\mathrm{HCl}$ and iron. Compound ( I ) represents the reactive intermediate of metronidazole.

Compound ( II ) $\left\{Y_{-}\left(\mathrm{r}_{-}\right.\right.$-methyl-o-[( $\Sigma^{\prime}-$ hydroxyphenyl)azo]- $1 \mathrm{H}$-imidazole- $\mathrm{lyl}$ )ethanol\} and compound ( III ) $\left\{r_{-}\left(Y_{-}\right.\right.$methyl-o[( $\{$ 'hydroxy-r'-methyl phenyl)azo]- $) \mathrm{H}$ imidazole- -yl)ethanol\} were prepared by diazotization of compound I and then coupling with phenol and o-cresol respectively.

The antibacterial activity of these compounds (I, II and III) was tested against: Staphylococcus aureus, Strepto-coccus pneumoniae, Pseudomonas aeruginosa, Escherichia coli and Clostridium Perfringens by using different concentrations for each compound $\left(1 r^{\circ} 0, r_{0}, 0.1 \cdots\right.$ and $\left.r_{\cdots} \cdot \mathrm{mg} / \mathrm{ml}\right)$.
Triplet runs were carried out for each bacterial strain.

The results of this research showed that these compounds have no anti-bacterial activity against the tested bacteria at the concentrations used; and the reactive intermediate of metronidazole (compound I ) was only active when formed inside the anaerobic bacteria and inactive when applied directly to these micro-organisms.

In addition, the incorporation of azo linkage with phenyl ring containing electron-donating group(s) and with imidazole ring containing electron-donating groups may diminish the antibacterial effect of azo bond, as in compounds II )and III .

\section{References}

1. Martindale R.J., " The extra pharmacopoeia ", $r{ }^{\text {th }}$ ed. , 199r: 01 v-011.

r. Block H.J. and Beale M.J., Wilson and Gisvold's, " Textbook of organic medicinal and pharmaceutical chemistry ", $1{ }^{\text {th }}$ ed., $(r \cdots \varepsilon), p$ : r.

r. Edwards D.I., Nitroimidazole drugs action and resistance mechanisms. I. Mechanisms of action. J. Antimicrob. Chemother. 199r; $r 1: 9-$ ir.

๕. Edwards D.I., Reduction of nitroimidazoles in vitro and DNA damage. j. Biochem. Pharmacol. 1917; r0:0\%-0V.

- Muller M., Reductive activation of nitroimidazoles in anaerobic microorganisms. J. Biochem. Pharmacol. 191 ; ro: rV- $\varepsilon$.

7. Tocher J.H. and Edwards D.I., The interaction of reduced metronidazole with DNA bases and nucleosides. Int. J. Radiat. Oncol. Biol. Phys. 199\%; rY: т71-7тr.

v. Tocher J.H. and Edwards D.I., Evidence for the direct interaction of reduced metronidazole derivatives with DNA bases. J. Biochem. Pharmacol. $199 \varepsilon ; \wedge \varepsilon: 1 \cdot 19-1.94$.

^. Goldman P.; Koch R.L. and Yeung T.C., Comparing the reduction of nitroimidazoles in bacteria and mammalian tissues and relating it to biological activity. J. of Biochemical Pharmacology. 1917; ro: $\leqslant$ T- $\leqslant 9$.

9. Malagoli M.; Rossi T.; Baggio A.; Zandomenghi G.; Zanca A.; Casolari C. and Castelli M., In vitro study of chemotherapeutic activity of sulphimidazole on some sensitive and metronidazole resistance Trichomonas 
Vaginalis strains. Pharmacological Research. r.. r; $\{\tau: \leqslant 7 q-\varepsilon V r$.

1. Fang H.; Edlund C.; Hedberg M. and Nord C., New findings in beta-lactam and metronidazole resistant Bacteroides Fragilis. International $\mathrm{J}$. of Antimicrobial Agents. r... r; 19: rч) $r v \cdot$.

1'.Rafi F.; Wynne R.; Heinze T. and Paine D., Mechanism of metronidazole resistance by isolates of nitroreductase-producing Enterococcus Gallinarum and Enterococcus Casseliflavus from the human intestinal tract. FEMS Microbiology Letters. r...r; rro: $190_{-}$ Y...

1Y.Pituch H.; Wultanska D.; Belkum A. and Luczak M., Laboratory diagnosis of antibioticassociated diarrhea: a polish pilot study into the clinical relevance of Clostridium Difficile and Clostridium Perfringens toxins. Diagnostic Microbiology and Infectious Diseases. r... $0 \wedge: \vee 1-v 0$.

Ir.Boyanova L.; Gergova G.; Nikolov R.; Davidkov L.; Kamburov V.; Jelev C. and Mitov L., Prevalence and evolution of Helicobacter Pylori resistance to 7 antibacterial agents over 1 years and correlation between susceptibility testing methods. Diagnostic Microbiology and

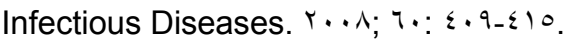

I乏. Kulda J., Trichomonads, hydrogenosomes and drug resistance International. J. of Parasitology. 1999; rq:। $99-r / r$

10. Rasoloson D.; Tomkov E.; Cammack R.; Kulda J. and Tachezy J., Metronidazole-resistant strains of Trichomonas vaginalis display increased susceptibility to oxygen. J. of Parasitology. r.. 1; rr: $\{0.07$.

17. Quon D.V.; Oliveira C.E. and Johnson P.J., Reduced transcription of the ferredoxin gene in metronidazole-resistant Trichomonas vaginalis. Proc. Natl. Acad. Sci. USA. 199r; $\wedge १: \varepsilon \varepsilon \cdot r_{-} \varepsilon \varepsilon \cdot \tau$.

IV. Kirkwood M.L. and Patricia J.J., Molecular basis of Metronidazole resistance in pathogenic bacteria and protozoa. Drug

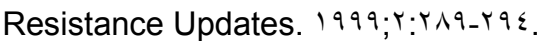

^^. Cerkasov J.; Kulda J. and Tachezy J., Metabolic properties of Trichomonas vaginalis resistant to metronidazole under anaero-bic conditions. Acta. Univ. Carol. Biol. 19^v;r $\because$ $0.0 .01 r$.
19. Morrison R. Th. and Boyd R.N., " Organic Chemistry ", rrd ed., 19V乡:Vrv-VrA. 19**. Morrison R. Th. and Boyd R.N., " Organic

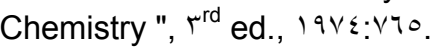

$r$.Vogel A.l., " Textbook of practical organic chemistry ", r rd ed., 197r:7r.

r). Child R.G.; Wilkinson R.G. and Tomcu-Fucik A., Effect of substrate orientation of the adhesion of polymer joints. Chem. Abstr. 19VV; $\wedge V: T \cdot r \cdot-7 \cdot r \varepsilon$.

r..Garg H.G. and Praksh C., Preparation of $\varepsilon-$ arylazo- $r, 0_{-} \quad$ disubstituted- $(r \mathrm{H})-\quad 1, r, r_{-}$ thiadiazine-1, 1-dioxides. J. Med. Chem. I $9 \mathrm{Y}$;

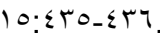

rr.Ahmed S.H.; Awad I.M.; Aly A.A.; Abdel Alim A.M. and Abdel Aal R.A., Synthesis of some --azo ( $\Sigma$ '-substituted benzene-sulphamoyl)-^hydroxyquinolines with antidotal and antibacterial activities. J. of Inorg. Bioch. 191^; r: $\vee v_{-} \wedge q$.

$r$ ¿.Sanjay F. Thakor; Dinesh M. Patel; Manish P. Patel and Ranjan G. Patel, Synthesis and antibacterial activity of novel pyrazolo $[r, \varepsilon, b]$ quinoline based heterocyclic azo compounds and their dyeing performance. Saudi Pharmaceutical J. Y..v; $0: \leqslant$ : _- 0 .

ro. Mohan Ch.; Saharia G.S. and Sharma H.R., Synthesis of I- aryl-r-methyl-r.(substituted sulphonamidobenzensaao)propane-

$1, \Gamma$ - diones and evaluation of their antibacterial properties. Def. Sec. J. 19v0; Y0:00_01.

r..Brooks G.F.; Butel J.S. and Morse S.A., " Medical Micro- biology ", $r^{\text {th }}$ ed., $\uparrow \ldots \varepsilon: 1 \uparrow \uparrow$.

rv.Budavari S., The Merck Index, " An eucyclopedia of chemicals, drugs and biologicals ", $11^{\text {th }}$ ed., 1919: $7 . \vee 9$.

r^.Beaulien B.B., Metronidazole metabolism in cultures of Entamoeba histolytica and Trichomonas vaginalis. Anti- microbial agents and chemotherapy. $1911 ; r \cdot: \varepsilon 1 \cdot-\varepsilon 1 \leqslant$.

rq. Moffat A.C., Clarke's, " Isolation and identification of drugs in pharmaceuticals, body fluids and post-mortem materials " , $r^{\text {nd }}$

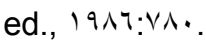

